\title{
Potret Aktivitas Makan dalam Leksikon Jawa dan Nilai Filosofi
}

\author{
M. Suryadi \\ Fakultas Ilmu Budaya, Universitas Diponegoro \\ mssuryadi07@gmail.com
}

\begin{abstract}
The purpose of this study is to prove that there is a relationship between eating activities and the behavior of coastal Javanese in Semarang City. This correlation study involves the relationship of the form of the lexicon to the concept of the lexicon and the value of Javanese philosophy. Research Location in the Central Java Coastal Region, a locus of research in the city of Semarang. This type of research is descriptive qualitative. Data collection methods used were observation, documentation, and active participation through in-depth interviews. The analytical method used is the lexicon mapping based on the form of unit - cultural values - references. The consideration used to map the lexicon is the cultural value in Javanese tradition. The theory used is the reconstruction of the lexicon in the meaning group of eating activities. The findings of the study are the self-identity of the eating activity lexicon has a correlation with Javanese human behavior, especially in socializing with the community. The lexicon of eating activity, preserving the values of Javanese culture in contact with politeness..
\end{abstract}

Keywords : Culture; eating activities; Javanese philosophy; lexicon.

\section{Intisari}

Penelitian ini bertujuan untuk menilik hubungan erat antara aktivitas makan dengan perilaku masyarakat Jawa yang memiliki kultur Jawa Pesisiran di Kota Semarang, keeratan hubungan ini ditinjau dari bentuk leksikon Jawa yang mengandung nilai filosofi Jawa. Lokasi Penelitian ada di wilayah Pesisir Jawa dengan lokus penelitian di Kota Semarang. Jenis penelitian adalah deskriptif kualitatif. Metode pengumpulan data yang digunakan adalah observasi, documentasi, dan partipasi aktif melalui wawancara mendalam. Metode analisis yang digunakan adalah pemetaan leksikon melalui perangkat bentuk-konsep-nilai kultural-referent dengan mempertimbangan arti semantic dalam tradisi Jawa. Teori yang digunakan berupa rekonstruksi leksikon pada medan makna aktivitas makan. Temuan penelitian adalah identitas diri leksikon pada aktivitas makan memiliki korelasi kedekatan dengan perilaku manusia Jawa dalam bersosialisasi dalam kehidupannya. Kultur Jawa selalu melekat pada aktivitas makan yang bersentuhan dengan adab kesantunan.

Kata Kunci : Aktivitas makan; filosofi Jawa; kultur; leksikon. 


\section{Pendahuluan}

Kehidupan manusia tidak dapat dilepaskan dengan kebutuhan dasar berupa sandang dan pangan. Terutama kebutuhan pangan sebagai kebutuhan mendasar dan kebutuhan hakiki yang azasi dalam diri manusia (Suryana 2005). Sebagai kebutuhan dasar yang harus dipenuhi kerap kali manusia harus bekerja keras agar keluarga yang dihidupi dapat terjamin kesehatan dan kelayakan hidupnya (cf. Pusat Kebijakan Perdagangan Dalam Negeri 2013; DKP 2014). Sebagai kebutuhan dasar yang harus tersedia kerapkali akan menyangkut harkat martabat seseorang yang memiliki persoalan-persoalan mendasar, termasuk di dalamnya bagaimana cara pemerolehannya, bagaimana cara pengolahannya, dan bagaimana cara membudidayakan (Saliem and Ariani 2016). Kebutuhan harkat inilah dalam masyarakat Jawa akan ditata dalam tatanan sosial dan tatanan adat dalam kultur budaya.

Masyarakat Jawa yang selalu menjunjng tinggi adat dan nilai budaya terpotret dari rasa hormat dan kepatuhan dalam adatnya (Konsep Diri Dalam Budaya Jawa 2016), tertuang dalam konsep rumangsa melu anduweni dan wajib melu angkrungkebi. Setiap tatanan ini akan tersimpan baik secara tertulis atau tersimpan secara konvensional. Kehidupan masyarakat Jawa yang mengutamakan keselarasan hidup antarsesama (relationship between humans) (Sartini 2009), keharmonisan dengan alam (Rukesi and Sunoto 2017), kepatuhan dengan norma/adat (cf. (Arimbawa and Santhyasa 2010). Prinsip-prinsip ini selalui dipatuhi atau diugemi. Kepatuhan tersebut terpotret dalam semua kegiatan hidup mulai dari irama daur kehidupan, penataan ruang dan tempat tinggal, penamaan identitas personal, sampai pada penataan makan dan makanan.

Penataan makan dan makanan dalam kehidupan masyarakat Jawa tradisional pedalaman memiliki perhitungan sacral (Giri 2010) dan tatanan ruang (Kartono 2005). Keunikan inilah sisi kearifan local dan keluhuran budi masyarakat Jawa terdapat dalam semua lini. Makan dan makanan adalah dua kata yang saling terkait dan tidak dapat dipisahkan. Makan terkait dengan aktivitas sedangan makanan terkait dengan objeknya. Makan lebih terfokus pada aktivitas di mana masyarakat Jawa melakukan sesuatu: cara aktivitas makan, alat makan, organ makan, dan perilaku makan. Penelitian ini lebih memfokuskan pada cara aktivitas makan yang dilakukan oleh masyarakat Jawa, khususnya masyarakat Jawa Pesisir di Kota Semarang. 
Adapun rumusan masalah yang diangkat pada penelitian ini adalah bagaimana aktivitas makan masyarakat Jawa Pesisir yang dapat dipotret melalui bentuk leksikonnya, dengan merekonstruksi bentuk leksikon tersebut berdasarkan konsep kultural yang bertahan di masyarakat Jawa pesisir. Tujuan yang selaras dengan rumusan masalah adalah mendeskripsikan leksikon-leksikon bahasa Jawa yang menyimpan konsep keluhuran budi yang bermedan makna aktivitas makan bagi masyarakat Jawa Pesisiran.

Kecermatan dan ketajaman penelitian didukung dengan refrensi atau rujukan ilmiah. Beberapa refensi yang digunakan untuk mempertajam analisis sebagai berikut.

Idrus (2012) dalam karyanya Pendidikan Karakter pada Keluarga Jawa mengungkap keprihatian pada masyarakat Jawa (perkotaan) yang mengalami penurunan etika, moral, dan karakter bangsa. Gejala ini harus segera diatasi melalui penanaman proses pendidikan yang membentuk karakter luhur mulai dari awal pengasuhan dan menjadi rantai kesinambungan yang tak terputus hingga dewasa agar keluhuran budi tetap tertanam. Karya ini dimanfaatkan sebagai tolok ukur kehidupan modern perkotaan apakah tetap rindu dengan keluhuran budi yang tertanam pada tatalaksana makan dan makanan dalam lingkungan keluarga muda.

Purwadi (2011) dalam karyanya Etika Komunikasi dalam Budaya Jawa mengungkapkan sistem komunikasi yang dilakukan manusia Jawa dalam berinteraksi sosial memiliki aturan yang harus dipenuhi, sehingga saling menghargai dan saling menghormati selalu terjaga. Sistem komunikasi interaksi sosial masyarakat Jawa akan muncul atuaran yang berupa unggah-ungguh, suba-sita, tata-krama, tata-susila, sopan-santun, yang digunakan untuk menanamkan dan menjaga budi pekerti. Karya ini sangat dimanfaatkan untuk mengetahui keketatan norma dalam setiap langkah kegiatan yang terkait dengan hubungan sosial dan kesantunan. Perilaku ini juga terjaga dalam tatalaksana jamuan makan dalam kultur Jawa. Jamuan makan yang melibatkan banyak orang selalu tertata dalam adat dan budaya, semua tatanan tersebut juga terpotret dalam aktivitas makan dalam jamuan atau hajat penerimaan tamu.

Bakti Mardikantoro (2013) dalam karyanya Bahasa Jawa sebagai Pengungkap Kearifan Lokal Masyarakat Samin di Kabupaten Blora mengungkap hubungan antara bahasa dan budaya pada masyarakat penuturnya. Bahasa yang digunakan oleh masyarakatnya tidak lepas dari kekayaan kearifan lokal, diantaranya larangan mengumbar hawa nafsu, berbakti kepada orang 
tua atau yang dituakan, kejujuran, hukum karma, pelestarian lingkungan, dan etos kerja. Karya ini digunakan sebagai rujukan bahwa semua yang ada dalam fenomena alama baik yang konkrit maupun abstrak akan tersimpan dalam bahasa atau tuturannya (leksikon). Dengan memahami unsur leksikonnya dapat terpotret keadaan masyarakat pengguna bahasa tersebut.

Geeraerts (2009) dalam karyanya Theories of Lexical Semantics mengungkapkan bahwa kekomprehensifan teori semantik leksikal dalam beberapa lintasan kajian, mulai kajian awal semantik historis-filologis, semantik strukturalis, semantik generatif, semantik neostrukturalist, dan semantik kognitif. Lintasan kajian ini tetap tersentra leksikon-leksikon dalam teks. Refernsi buku teks ini memberikan inspirasi bahwa kajian semantik dalam sebuah kata dapat dilakukan dengan alih lintasan agar kajian dapat lebih komprehensif dan tajam.

Bisetto (1997) dalam bukunya The Generative Lexicon mengupas bahwa dalam kajian mutakhir leksikon generatif adalah teori semantik yang lebih memfokuskan pada mobilitas distribusi (komposisionalitas) dalam bahasa. Sehingga beban semantis pada setiap leksikon tidak hanya diletakkan pada leksikon itu sendiri, namun juga diletakkan dimana leksikon itu berada dan lingkungan tempat leksikon itu ditempatkan. Buku refernsi ini sangat bermanfaat untuk mensuplay setiap kandungan semantik yang dipikul oleh leksikon itu sendiri. Dengan demikian, setiap leksikon dapat diinterpretasikan nilai semantisnya dengan mendasarkan komposisionalitasnya.

\section{Metode Penelitian}

Lokasi penelitian di Kota Semarang, yang lebih difokuskan pada wilayah perkampungan pesisir, wilayah yang akrab dengan komunitas nelayan. Dengan demikian, lokus penelitian berada di wilayah Semarang Bagian Utara.

Jenis penelitian ini deskriptif kualitatif yang mengeksplore kegiatan aktivitas makan dalam bidikan leksikon yang dimiliki dan digunakan dalam tuturan sehari-hari di masyarakat pesisiran Kota Semarang. Dengan demikian, ancangan penelitian yang digunakan adalah linguistik deskriptif-eksploratif yang lebih memfokuskan identifikasi leksikon dan varian leksikon serta memperhatikan konsep yang diemban leksikon tersebut dan referent yang 
dipilih. Disamping itu,masih mempertimbangkan sosikultural masyarakat Jawa pesisir yang menyimpan nilai dan ruh kultural Jawa.

Data dalam penelitian ini meliputi data primer dan data sekunder. Data sekunder digunakan untuk mendukung data primer. Pengumpulannya dilakukan dengan menggunakan metode observasi, interviu (structured interview dan in-depth interview) (Sudaryanto 1993).

Data penelitian dianalisis dengan menggunakan beberapa ancangan dan tahapan. Hal ini dilakukan dengan harapan data dapat dianalisis dengan komprehensif dan tajam. Data yang terdapat dalam korpus linguistic akan dipilih dengan teknik pilah yang memanfaatkan intuisi kultural masyarakat Jawa Pesisir. Data terpilih akan ditentukan lema dan sublema untuk menentukan meaning leksikalnya. Data selanjutnya diolah dengan generative leksikal yang memadukan beban semantiknya pada nilai konsep kultural dan referent yang diacu dalam ektralingualnya. Diharapkan potret leksikon Jawa dapat menjelaskan muatan semantisnya terhadap nama yang melekat dalam setiap leksikonnya.

\section{Hasil dan Pembahasan}

Kebutuhan hakiki manusia yang paling dasar untuk dapat hidup adalah makan. Manusia dapat hidup sehat salah satu faktor utama adalah pola makan. Dalam pola makan terdapat unsur perilaku makan, jenis makanan, pengolahan makanan, intensitas makan, dan selera makan. Pada penelitian ini, lebih difokuskan pada perilaku makan, yang terkait dengan aktivitas makan, terutama yang berhubungan dengan cara makan, yakni cara makan masyarakat Jawa pesisir

\section{Makanan Jawa Khas Semarang}

Makanan Jawa khas Kota Semarang adalah masakan makanan Jawa yang banyak ditemui dan terkenal di Kota Semarang, sebagai wilayah Pesisir. Pada kajian ini tidak mempertimbangkan asal-usul makanan tersebut berasal. Dengan demikian, yang menjadi bahan pertimbangan adalah makanan yang banyak dikenal dan menjadi kegemaran sekaligus ikon masyarakat Kota Semarang. Beberapa makanan yang terkenal di Kota Semarang, antara lain, gudangan, gandos, mie kopyok, dan blenyik.

\section{Gudangan}


Gudangan adalah salah satu makanan tradisional yang terfavorit di Kota Semarang. Jenis makanan ini banyak dijumpai atau banyak dijual di pasar-pasar tradisional. Gudangan atau nama lainnya klubanan makanan tradisional yang berupa sayur-sayuran matang yang berbumbu dasar sambal parutan kelapa muda. Makanan ini kerap kali dihidangkan pada waktu-waktu penting tertentu atau upacara-upacara tertentu, misal acara tasyakuran, hajatan, kondangan, dan slametan. Makanan ini disajikan bersama dan dihidangkan bersama-sama. Hidangan bersama ini lebih nikmat bila makana bersama dengan cara muluk (tangan muluk).

\section{Gandos}

Gandos adalah salah satu jajanan tradisional khas Kota Semarang. Makanan ini kerapkali dijajakan di pasar-pasar tradisional atau dikeliling-lingkan ke kampong-kampung dengan di dorong menggunakan gerobak atau lebih modern dengan menggunakan sepeda kayuh (sepeda ontel). Jajanan Gandos sangat disukai selain rasanya enak harganya sangat murah. Jajanan gandos lebih enak dimakan saat panas atau hangat, dengan bungkusan daun. Cara makan jajanan gandos dengan cara dimamah pelan-pelan untuk dapat dinikmati kehangatan dan kegurihan rasanya.

\section{Mie Kopyok}

Mie Kopyok adalah makanan khas dan tradisional masyarakat Semarang. Sebutan nama Mie Kopyok beranalogi dengan cara pembuatannya, yakni dicelup dan dikopyokkan ke air dandang panas dan atau kopyokkan air bawang dalam botol. Mie Kopyok sebagai makanan tradisional dijajakan keliling kampung dengan cara didorong gerobak atau dipikul. Makanan ini tergolong sebagai makanan sayur berkuah dengan taburan kerupuk karaka tau gendar. Mie Kopyok akan terasa nikmat bila dihidangkan saat hangat atau sedikit panas. Cara makannya dengan disuru atau disendok.

\section{Blenyik}

Blenyik adalah makanan tradisional khas Kota Semarang. Blenyik tergolong lauk atau gadon / gadonan. Jenis gadonan ini sangat popular di masyarakat Semarang. Makanan yang berbahan dasar ikan teri yang diolah dan dibuat bentuk bulat. Blenyik sebagai makanan khas kota Semarang selain banyak dijual pada pasar-pasar tradisional, sekarang sudah dikemas dalam bentuk oleh-oleh khas Semarang dan dijajakan di toko-toko besar yang menjajakan oleh-oleh 
khas Semarang. Godon Blenyik sangat nikmat dimakan sebagai lauk dengan nasi hangat dan sambal pedas. Cara makan gadon Blenyik dengan cara dicuwil-cuwil dsedikit demi sedikit.

\section{Aktivitas Makan terkait dengan Tekstur Makanan}

Aktivitas makan adalah semua kegiatan manusia yang terkait dengan pemunuhan kebutuhan hidup yang berupa asupan makanan sebagai kebutuhan dasar hidup dan kelangsungan hidup. Aktivitas makan setiap manusia adalah sama yakni memberikan asupan tubuh akan terpenuhi kebutuhan dasar tubuh untuk menjaga metabolismenya. Hal yang paling membedakan pada kegiatan aktivitas makan pada setiap manusia lebih banyak ditentukan oleh faktor internal dan eksternal. Masing-masing faktor tersebut dapat diperinci seperti pada bagan berikut ini.

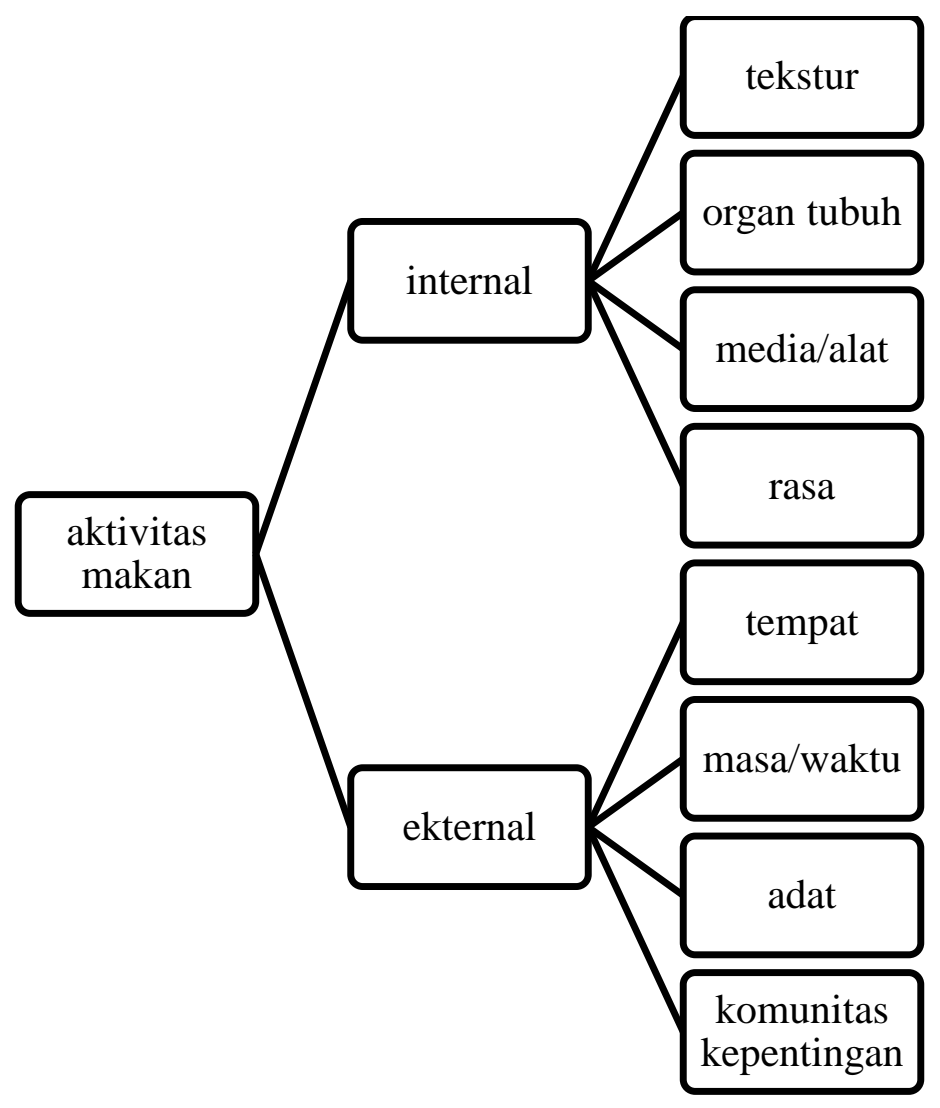

Berdasarkan faktor penentunya, aktivititas makan yang terkait dengan tekstur makanan dapat dipilahkan sebagai berikut.

\section{Muluk}


Leksikon muluk memiliki bentuk dasar puluk dengan beberapa bentuk derivasinya antara lain muluk, dipuluk, dan puluken. Kata muluk memiliki arti leksikal mengambil sesuatu (bahasa Jawa: jupuk) dan setinggi-tingginya (bahasa Jawa: muluk,dhuwur).

Kehidupan tradisi Jawa aktivitas makan muluk memiliki konsep makan dengan menggunakan tangan dengan mengotimalkan satu kesatuan lima jari tangan dalam mengambil makan untuk diasupkan dalam mulut. Aktivitas muluk tanpa bantua alat apapun (seperangkat suruh atau sendok). Kelima jari tangan sebagai satu kesatuan yang memiliki gerak saling melengkapi. Nilai filosofi yang tertanam dalam aktivitas muluk adalah (1) mengambil secukupnya tidak berlebihan dan (2) menghargai apa yang sudah diambil dan diangkat mengadah ke atas sebagai ucapan syukur. Kedua filosofi ini sebagai pesan yang akan disampaikan bahwa sesuatu yang diperoleh dengan daya upaya dan kerja keras harus dapat dimanfaatkan semaksimal mungkin.

Potret yang tertanam pada masyarakat Jawa bahwa pada acara hajatan atau selamatan atau kenduri semua hidangan yang disajikan kepada tetamu akan ditata dalam ancak 'anyaman tradisional tempat makanan' dan dinikmati bersama dengan tradisi pulukan. Semua hidangan yang disajikan akan dihabiskan dengan bersih bahkan yang tersisa akan dipuluki. Semua hidangan akan berkah sebagai bentuk rasa syukur masyarakat Jawa Pesisir. Beberapa ungkapan yang terkait dengan kata muluk yang banyak dijumpai di wilayah pesisiran, sebagai berikut.

1) Larang sega muluk upa

'mahal nasi mengambil bulir nasi'

2) Sakpulukan wis ngeraketake pasuduluran

'satu sendok sudah merekatkan persaudaraan'

3) Sakpuluk sega luwih aji tinimbang gembok

'satu sendok nasi lebih baik daripada pintu gerbang'

\section{Pamah}

Leksikon pamah dengan bentuk derivasinya mamah, dipamah, dan kepamah. Aktivitas mamah memiliki arti leksikal mengunyah, melumat, menghaluskan. Konsep aktivitas mamah dalam bahasa Jawa adalah mengunyah makanan yang masuk ke mulut sebelum ditelan. Dalam bahasa Jawa ungakapan yang terkait dengan leksikon mamah yakni, sebagai berikut. 
1) Ora obah ora mamah

'tidak bergerak tidak dapat rejeki'

2) Ana dina ana upa, gelem ubah isa mamah.

'ada hari ada nasi, mau bergerak mendapatkan rejeki'

3) Obahe kenceng mamahe kuwat

'kerjanya kuat rejekinya banyak'

Berdasarkan ungkapan Jawa tersebut, leksikon mamah memeiliki nilai filosofi yang sangat dalam, yakni pekerjaan atau karya yang mendatang rejeki untuk mencukupi kebutuhan hidup diri sendiri atau keluarga. Etos pekerjaan Jawa adalah kekuatan semangat yang tinggi, karena alam Jawa Dwipa sudah menyediakan kesuburan dan kemakmuran yang lebih dari cukup. Setiap orang Jawa mau bekerja apapun, dipastikan akan memperoleh rejeki yang diperlukan. Sehingga ada pepatah juga yang terkait dengan pekerjaan dan kemakmuran alam, yakni.

1) Gelem nandur mesti thukul.

'mau menanam akan tumbuh/memetik hasilnya'

2) Gelem macul entuk wakul.

'mau bekerja mendapatkan hasil'

3) Gelem gasik kebagian.

'bila mau lebih awal pasti mendapat bagian'

Dengan demikain leksikon mamah memiliki nilai filosofi yang kuat terhadap keyakinan kerja bagi masyarakat Jawa. Beberapa petuah yang bernilai tinggi terhadap nilai keluhuran budi, yakni pada ungkapan berikut. Mamahen kanthi ati-ati aja nganti ilatmu melu kecokot 'kunyahlah dengan hati-hati hangan sampai lidahmu ikut tergigit'. Filosofi ungkapan ini memberikan nasihat luhur bahwa bila bekerja harus cermat dan sungguh-sungguh, jangan sampai merugikan orang lain.

\section{Disuru}

Leksikon suru dalam masyarakat Jawa dikenal sebagai piranti atau alat bantu untuk makan atau sendok daun pisang. Kata suru memiliki arti leksikal sendok, ambil, ciduk. Konsep yang dimiliki dalam bahasa Jawa adalah sendok daun pisang, yang biasa disobekkan dari tempat pembungkus, dengan ukuran $2-3 \mathrm{~cm}$, yang dilipat jadi dua. 
Suru godhong gedang 'sendok daun pisang' dalam kultur Jawa memiliki nilai filosofi yang tinggi dan luhur, sekaligus sebagai potret kesederhanaan masyarakat Jawa sekaligus potret kesehatan dan keharmonisan lingkungan. Sendok suru memiliki nilai filosofi sebagai kekuatan insan Jawa dalam mengahadapi kenyataan hidup, yakni:

a. Mau berkorban sebelum meraih kesuksesan. Filosofi ini ditandai bahwa sendok suru selalu diambil atau disobekkan pada bagian pembungkusnya. Makna sobek inilah sebagai lambang mau mengorbankan diri dalam sebuah perjuangan.

b. Tahan terhadap persoalan. Filosofi ini ditandai bahwa sendok suru digunakan untuk mengambil makanan yang panas (bubur) atau makanan yang dingin atau makanan yang berkuah. Ketahanan inilah sebagai lambang tahan mengahadapi persoalan.

c. Keiklasan, bentuk keikhalasan ditandai dengan bahwa setelah sendok suru digunakan maka akan dibuang bersama pembungkusnya. Dibuang jadi satu dengan pembungkusnya sebagai lambang bahwa segala sesuatu yang dilakukan dengan kebaikan tidak boleh dingat-ingat kembali.

Kekuatan nilai filosofi aktivitas makan menandakan bahwa keluhuran budaya Jawa yang menyimpan nilai-nilai luhur baik berupa kecerdasan sosial, kearifan local, maupun kekuatan kualitas hidup akan selalu terpotret dalam identitas penamaan leksikon. Setiap leksikon dalam tatanan budaya Jawa diturunkan dengan perangkat kultur yang berlapis-lapis. Kekuatan inilah yang memiliki daya tahan dan reliksitas leksikon Jawa.

\section{Simpulan}

Nilai filosofi yang tertanam dalam setiap wilayah memiliki nilai keluhuran yang berbeda-beda. Nilai keluhuran ini lebih banyak ditentukan oleh aktivitas masyarakatnya dalam memahami kehidupan, mengahadapi alam, memanfaatkan alam, dan keberlangsungan hidup yang turun temurun. Proses ini akan terpotret pada setian penamaan leksikon. Leksikon aktivitas makan yang terkait dengan kebutuhan mendasar dan kebutuhan hakiki dalam masyarakat Jawa memiliki nilai filosofi yang tinggi dan luhur. Nilai filosofi yang melekat pada leksikon aktivitas makan dapat diurai dengan kemampuan rekontruksi semantik yang memadukan dengan konsep-konsep Jawa dalam kulturnya, termasuk dalam kata muluk, mamah, dan suru. 


\section{Daftar Pustaka}

Arimbawa, Wahyudi, and I Komang Gede Santhyasa. 2010. "Perpektif Ruang sebagai Entitas Budaya Lokal Orientasi Simbolik Ruang Masyarakat Tradisional Desa Adat." Local Wisdom-Jurnal Ilmiah Online, Issn: 2086-3764.

Bakti Mardikantoro, Hari. 2013. "Jurnal Komunitas Bahasa Jawa Sebagai Pengungkap Kearifan Lokal Masyarakat Samin di Kabupaten Blora Javanese as Expression of Local Wisdom in Samin Community Blora.” Jurnal Komunitas. https://doi.org/10.15294/komunitas.v7i1.3622.

Bisetto, A. 1997. "The Generative Lexicon.” Lingua e Stile.

DKP. 2014. "Pangan Untuk Indonesia." Indonesia Policy Briefs.

Geeraerts, Dirk. 2009. Theories of Lexical Semantics. https://doi.org/10.1093/acprof:oso

Giri, Wahyana. 2010. Sajen Dan Ritual Orang Jawa. 1st ed. yogyakarta: Narasi.

Idrus, Muhammad. 2012. "Pendidikan Karakter Pada Keluarga Jawa." Jurnal Pendidikan Karakter.

Kartono, J. Lukito. 2005. “Konsep Ruang Tradisional Jawa Dalam Konteks Budaya.” Dimensi Interior.

"Konsep Diri Dalam Budaya Jawa." 2016. Buletin Psikologi. https://doi.org/10.22146/bpsi.11946.

Purwadi. 2011. "Etika Komunikasi Dalam Budaya Jawa." IKADBUDI (Ikatan Dosen Budaya Daerah Se-Indonesia).

Pusat Kebijakan Perdagangan Dalam Negeri. 2013. "Analisis Dinamika Konsumsi Pangan Masyarakat Indonesia." Kementerian Perdagangan RI.

Rukesi, Rukesi, and Sunoto Sunoto. 2017. "Nilai Budaya dalam Mantra Bercocok Tanam Padi di Desa Ronggo, Kecamatan Jaken, Kabupaten Pati, Jawa Tengah: Kajian Fungsi Sastra." BASINDO: Jurnal Kajian Bahasa, Sastra Indonesia, Dan Pembelajarannya. https://doi.org/10.17977/um007v1i12017p025.

Saliem, Handewi Purwati, and Mewa Ariani. 2016. "Ketahanan Pangan, Konsep, Pengukuran Dan Strategi." Forum Penelitian Agro Ekonomi. https://doi.org/10.21082/fae.v20n1.2002.12-24.

Sartini, ni wayan. 2009. "Menggali Nilai Kearifan Lokal Budaya Jawa Lewat Ungkapan (Bebasan, Saloka, Dan Paribahasa).” Universitas Airlangga, 2009.

Sudaryanto. 1993. Metode Dan Aneka Teknik Pengumpulan Data. yogyakarta: Gajahmada University Press.

Suryana, Achmad. 2005. "Kebijakan Ketahanan Pangan Nasional." Simposiun Nasional Ketahanan Pangan Pada Era Otonomi Dan Globalisasi. 